\title{
Irritants and asthma
}

\author{
Lidia Casas and Benoit Nemery
}

Affiliations: Dept of Public Health and Primary Care, Centre for Environment and Health, KU Leuven, Leuven, Belgium.

Correspondence: Benoit Nemery, KU Leuven, Pneumology, Herestraat 49 (706), Leuven, B-3000, Belgium. E-mail: Ben.Nemeryamed.kuleuven.be

0 @ERSpublications

If workplace exposures contribute to asthma, then they are too high and should not be considered low or moderate http://ow.ly/xwPuI

Asthma is a complex entity and one of the most common disorders in the world, affecting much of the workforce [1]. Asthma prevalence in children and adults has shown an increasing trend in the last decades $[2,3]$, which makes this disorder a major public health concern. Nevertheless, the mechanisms for the high incidence are not yet completely understood. In this regard, epidemiological studies focused on occupational asthma may contribute to unravelling the complexity of the disorder and the agents related to its onset and development.

Work-related asthma has been classified as comprising two main entities: sensitiser-induced asthma and irritant-induced asthma (IIA) [4]. The first involves a specific immunological response to a workplace sensitiser. These sensitisers are high-molecular-weight agents acting via the production of specific $\operatorname{IgE}$ antibodies or low-molecular-weight chemicals acting via other, hitherto less clarified immunological pathways [5-8]. The term IIA refers to asthma caused by exposure to agents that, when inhaled, act as respiratory irritants in the absence of sensitisation $[9,10]$. In the 1980s, BROOKs et al. [11] described reactive airway dysfunction syndrome. This diagnosis required very strict criteria that restricted the syndrome to the onset of asthma-like symptoms within $24 \mathrm{~h}$ after a single, very high exposure to an irritant agent. However, further studies suggested that repeated exposure to lower levels of irritants may also play a role in the onset of asthma after a longer latency period [10, 12-15]. Consequently, the American College of Chest Physicians guidelines recommended including in the IIA entity cases with a lag of several days before the onset of symptoms and repeated exposures over days or weeks [9]. A consensus report on IIA elaborated by a task force of the European Academy of Allergy and Clinical Immunology, in which many European Respiratory Society members took part, has recently been released [16].

This issue of the European Respiratory Journal contains an article by DuMAS et al. [17], who investigated, in a cross-sectional study of a large sample of Estonian adults, the associations between asthma and occupational exposure to known asthmagens or irritants. From about 50000 individuals recruited between 2002 and 2011 at the Estonian Genome Center of the University of Tartu, Dumas et al. [17] included 34015 adults aged 18-65 years, excluding participants who had never worked, those without job codes and those with imprecise job codes. "Asthma ever" was determined by self-report using a standardised questionnaire, with more rigorous asthma definitions also being considered, such as (reported) doctor-diagnosed asthma and currently treated asthma. Potential exposure to asthmagens was assessed by an asthma-specific jobexposure matrix [18]. Of course, no study is perfect, and this cross-sectional study without firm demonstration of asthma and without documentation of exposures is no exception. Nevertheless, these limitations are compensated by the large number of subjects, the representativeness of the sample for the

Received: May 152014 | Accepted: May 202014

Support statement: Lidia Casas is the recipient of a long-term research fellowship from the European Respiratory Society (grant LTRF 2013-1657). Benoit Nemery's research on occupational asthma is funded in part by the Interuniversity Attraction Pole Programme (P7/30), Belgium.

Conflict of interest: Disclosures can be found alongside the online version of this article at www.erj.ersjournals.com

Copyright @ERS 2014 
general population, the reasonably good assessment of past occupational exposures and the thorough statistical analysis.

In this study [17], 1062 individuals reported ever having asthma, with half of them reporting physiciandiagnosed asthma, almost three quarters reporting current asthma and half reporting current asthma treatment. The prevalence of exposure to known asthmagens was $20 \%$, and $17 \%$ were repeatedly exposed to low levels of irritants in their workplace. After adjustment for potential confounders, the authors showed that exposure to known asthmagens (in particular to high-molecular-weight agents) was associated with higher asthma prevalence. In addition, a significant $80 \%$ higher odds of physician-diagnosed asthma was found in individuals repeatedly exposed to low levels of irritants, when compared with individuals not exposed to any asthmagen. These associations with specific agents were further confirmed by analyses using occupation as exposure variable.

The findings in this population with a still relatively low background prevalence of asthma are in line with previous investigations, mostly conducted in western countries. They confirm previous reports on the association between occupational exposure to known asthmagens and asthma onset [19-22]. Nevertheless, the most relevant observation reported by DuMAs et al. [17] is the evidence of significant associations between repetitive exposures to low-to-moderate levels of irritants and asthma.

As shown by Dumas et al. [17], repeated exposure to low-to-moderate levels of irritants at work is common. Almost two out of 10 workers in this Estonian study population were exposed. Nevertheless, the number of epidemiological studies investigating the associations between this type of exposure and asthma is still limited and mainly focused on the exposure to cleaning agents [23]. An interesting case-control study from Taiwan pointed to the risk of asthma in people exposed to asthmagens, both sensitisers and irritants, at work [24]. Regarding cleaning agents, a study based on data from the European Community Respiratory Health Survey reported an increased risk of asthma in professional cleaners [25]. Further studies identified the use of bleach, ammonia or sprays at work and at home as risk factors for the onset of asthma [26-28]. Moreover, beyond the effects in active users, birth-cohort studies have demonstrated harmful effects of the household use of spray-applied cleaning agents in the development of children's respiratory system [29, 30]. Admittedly, the study by Dumas et al. [17] failed to detect a significant association between cleaning products and asthma. However, they observed two-fold increased odds of current physician-diagnosed asthma in professional cleaners compared with administrative and service jobs. In addition, they report a statistically significant association between physician-diagnosed asthma and low level of exposure to irritants, i.e. combustion particles/fumes, irritant gases/fumes or environmental tobacco smoke. The association estimates are as high as those obtained for known asthmagenic agents and higher for more specific definitions of asthma and exposure (current physician-diagnosed asthma, current treated physiciandiagnosed asthma and current job).

What lessons can we learn from this important epidemiological study? For clinicians, the message from this and many other studies is that exposure at work must always be considered in individual patients with asthma [31], and the potential causes must not only be sought among the traditional sensitisers but also among irritant chemicals. For the scientific community, this study should incite researchers to investigate further the role of irritants in the pathogenesis of asthma, possibly exploring pathways beyond the traditional paradigms of allergy and adaptive immunity [32]. Finally, for public health specialists and regulators, this study adds to the mounting evidence that asthma may be caused by what many people (including the authors of this editorial) call "low-to-moderate levels of irritants", in reality meaning "unmeasured levels that are common in many workplaces". If such exposures contribute substantially to disease, then they are too high and, consequently, they should no longer be considered low or moderate. This is not only a semantic issue.

\section{References}

1 To T, Stanojevic S, Moores G, et al. Global asthma prevalence in adults: findings from the cross-sectional world health survey. BMC Public Health 2012; 12: 204.

2 Asher MI, Stewart AW, Wong G, et al. Changes over time in the relationship between symptoms of asthma, rhinoconjunctivitis and eczema: a global perspective from the International Study of Asthma and Allergies in Childhood (ISAAC). Allergol Immunopathol (Madr) 2012; 40: 267-274.

3 James AL, Knuiman MW, Divitini ML, et al. Changes in the prevalence of asthma in adults since 1966: the Busselton health study. Eur Respir J 2010; 35: 273-278.

Tarlo SM, Lemière C. Occupational asthma. N Engl J Med 2014; 370: 640-649.

5 De Vooght V, Hox V, Nemery B, et al. Mechanisms of occupational asthma caused by low-molecular-weight chemicals. In: Sigsgaard T, Heederik D, eds. Occupational asthma. Progress in Inflammation Research. Basel, Birkhäuser/Springer, 2010; pp. 141-162.

6 Maestrelli P, Boschetto P, Fabbri LM, et al. Mechanisms of occupational asthma. J Allergy Clin Immunol 2009; 123: 531-542.

7 Malo JL, Chan-Yeung M. Agents causing occupational asthma. J Allergy Clin Immunol 2009; 123: 545-550. 

529-545.

9 Tarlo SM, Balmes J, Balkissoon R, et al. Diagnosis and management of work-related asthma: American College of Chest Physicians consensus statement. Chest 2008; 134: 1S-41S.

10 Brooks SM, Hammad Y, Richards I, et al. The spectrum of irritant-induced asthma: sudden and not-so-sudden onset and the role of allergy. Chest 1998; 113: 42-49.

11 Brooks SM, Weiss MA, Bernstein IL. Reactive airways dysfunction syndrome (RADS). Persistent asthma syndrome after high level irritant exposures. Chest 1985; 88: 376-384.

Tarlo SM. Irritant-induced asthma in the workplace. Curr Allergy Asthma Rep 2014; 14: 406.

Tarlo SM, Broder I. Irritant-induced occupational asthma. Chest 1989; 96: 297-300.

4 Kipen HM, Blume R, Hutt D. Asthma experience in an occupational and environmental medicine clinic. Low-dose reactive airways dysfunction syndrome. J Occup Med 1994; 36: 1133-1137.

15 Lemière C, Malo JL, Gautrin D. Nonsensitizing causes of occupational asthma. Med Clin North Am 1996; 80: 749-774.

16 Vandenplas O, Wiszniewska M, Raulf M, et al. EAACI position paper: irritant-induced asthma. Allergy 2014 [In press DOI: 10.1111/all.12448].

17 Dumas O, Laurent E, Bousquet J, et al. Occupational irritants and asthma: an Estonian cross-sectional study of 34000 adults. Eur Respir J 2014; 44: 647-656.

18 Kennedy SM, Le Moual N, Choudat D, et al. Development of an asthma specific job exposure matrix and its application in the epidemiological study of genetics and environment in asthma (EGEA). Occup Environ Med 2000; 57: 635-641.

19 Le Moual N, Carsin AE, Siroux V, et al. Occupational exposures and uncontrolled adult-onset asthma in the European Community Respiratory Health Survey II. Eur Respir J 2014; 43: 374-386.

20 Ghosh RE, Cullinan P, Fishwick D, et al. Asthma and occupation in the 1958 birth cohort. Thorax 2013; 68: 365-371.

21 Le Moual N, Kennedy SM, Kauffmann F. Occupational exposures and asthma in 14,000 adults from the general population. Am. J. Epidemiol 2004; 160: 1108-1116.

22 Lillienberg L, Andersson E, Janson C, et al. Occupational exposure and new-onset asthma in a population-based study in Northern Europe (RHINE). Ann Occup Hyg 2013; 57: 482-492.

23 Zock JP, Vizcaya D, Le Moual N. Update on asthma and cleaners. Curr Opin Allergy Clin Immunol 2010; 10: 114-120.

24 Wang TN, Lin MC, Wu CC, et al. Risks of exposure to occupational asthmogens in atopic and nonatopic asthma: a case-control study in Taiwan. Am J Respir Crit Care Med 2010; 182: 1369-1376.

25 Kogevinas M, Zock JP, Jarvis D, et al. Exposure to substances in the workplace and new-onset asthma: an international prospective population-based study (ECRHS-II). Lancet 2007; 370: 336-341.

26 Medina-Ramón M, Zock JP, Kogevinas M, et al. Asthma, chronic bronchitis, and exposure to irritant agents in occupational domestic cleaning: a nested case-control study. Occup Environ Med 2005; 62: 598-606.

27 Vizcaya D, Mirabelli MC, Antó JM, et al. A workforce-based study of occupational exposures and asthma symptoms in cleaning workers. Occup Environ Med 2011; 68: 914-919.

28 Zock JP, Plana E, Jarvis D, et al. The use of household cleaning sprays and adult asthma: an international longitudinal study. Am J Respir Crit Care Med 2007; 176: 735-741.

29 Casas L, Zock JP, Carsin AE, et al. The use of household cleaning products during pregnancy and lower respiratory tract infections and wheezing during early life. Int J Public Health 2012; 58: 757-64.

30 Casas L, Zock JP, Torrent M, et al. Use of household cleaning products, exhaled nitric oxide and lung function in children. Eur Respir J 2013; 42: 1415-1418.

31 Nemery B. Occupational asthma for the clinician. Breathe 2004; 1: 25-32.

32 Hox V, Vanoirbeek JA, Alpizar YA, et al. Crucial role of transient receptor potential ankyrin 1 and mast cells in induction of nonallergic airway hyperreactivity in mice. Am J Respir Crit Care Med 2013; 187: 486-493. 